\title{
Protein Hydrolysate from Splendid Squid (Loligo formosana) Fins: Antioxidant, Functional Properties, and Flavoring Profile
}

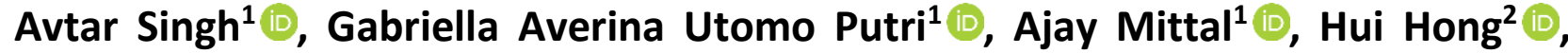 \\ Ahmet Faruk Yesilsu ${ }^{3}$, Soottawat Benjakul ${ }^{1, *}$
}

\begin{abstract}
${ }^{1}$ Prince of Songkla University, Faculty of Agro-Industry, International Center of Excellence in Seafood Science and Innovation (ICESSI), Hat Yai, Songkhla, 90110, Thailand.

${ }^{2}$ China Agricultural University, College of Food Science and Nutritional Engineering, Beijing Laboratory for Food Quality and Safety, Beijing, China.

${ }^{3}$ Central Fisheries Research Institute, Trabzon, Türkiye.
\end{abstract}

\section{How to cite}

Singh, A., Putri, G.A.U., Mittal, A., Hong, H., Yesilsu, A.F., Benjakul, S. (2022). Protein Hydrolysate from Splendid Squid (Loligo formosana) Fins: Antioxidant, Functional Properties, and Flavoring Profile. Turkish Journal of Fisheries and Aquatic Sciences, 22(6), TRJFAS21005. http://doi.org/10.4194/TRJFAS21005

\section{Article History}

Received 19 November 2021

Accepted 21 January 2022

First Online 25 January 2022

\section{Corresponding Author}

Tel.: +6674286334

E-mail: soottawat.b@psu.ac.th

\section{Keywords}

Splendid squid

Protein hydrolysate

Functional properties

Antioxidant activity

Flavor

\begin{abstract}
Protein hydrolysates (PH) from splendid squid fins (Loligo formosana) (SFPH) with different degrees of hydrolysis (DH) (10-40\%) were prepared using alcalase and characterized. The yield of SFPH was increased with increasing DH $(p<0.05)$. All SFPHs showed high protein content but low fat and ash contents. The lightness of SFPH was reduced with augmenting $\mathrm{DH}$ as advocated by increasing redness and yellowness $(p<0.05)$. All SFPH samples having $\mathrm{DH}$ above $10 \%$ exhibited relative solubility higher than $90 \%(p<0.05)$. Foaming properties of SFPH were also improved with increasing $\mathrm{DH}$. In general, antioxidant activities upsurged with increasing $\mathrm{DH}$, except metal chelating activity and DPPH radical scavenging activity, which were decreased at higher DHs. Molecular weight (MW) of peptides was lowered with increasing DH as measured by size exclusion chromatography and SFPH having DH 40\% (SFPH-40) possessed a higher proportion of peptides with smaller MW. SFPH-40 was rich in aspartic acid/asparagine and glutamic acid/glutamine. SFPH-40 had bitterness, especially at high concentrations. SFPH-40 contained a high number of volatile compounds associated with squid flavor. Thus, hydrolysates from squid fin could serve as an alternative nutrient with flavoring characteristics and antioxidant properties for food applications.
\end{abstract}

\section{Introduction}

Splendid squid (Loligo formosana) is an economically important and widely consumed seafood in Southeast Asian countries including Thailand (Singh, Mittal, \& Benjakul, 2020). During processing, low-valued by-products such as fins, heads, and guts are produced, which can create serious environmental pollution, if not disposed or managed properly. The by-products from the squid processing account for nearly $75 \%$ of the total catch weight (Shahidi, 2006). In general, those by-products are known to contain high-quality functional and nutritive components such as protein, polyunsaturated fatty acids (PUFAs), etc. (Singh, Benjakul, \& Kishimura, 2017). Squid processing by-products such as skin, fin, ovary, etc. are the excellent sources of proteins (Singh et al., 2017; Zlatanos et al., 2006), which can be used for protein hydrolysate production. Squid skin has been mostly exploited for collagen or its derivatives such as gelatin or its hydrolysates (Singh, Mittal, \& Benjakul, 2020). Nevertheless, less information has been available for the use of fin to produce protein hydrolysates $(\mathrm{PH})$.

Enzymatic hydrolysis of food proteins is an effective method to recover potent bioactive peptides as compared to the chemical and physical methods (Thiansilakul, Benjakul, \& Shahidi, 2007). Several commercial proteases including papain, alcalase, etc. have been employed to produce $\mathrm{PH}$. Among them, alcalase from Bacillus licheniformis is one of the most 
efficient and widely used proteases for hydrolysis of seafood proteins. It yielded hydrolysates with high bioactivities such as antioxidant activity, etc. as compared to other proteases ( Liu et al., 2010). In addition to the bioactivities, hydrolysis is also known to enhance the nutritional, physicochemical, and functional properties of the parent proteins (Singh \& Benjakul, 2019). Normally, interfacial properties (emulsifying and foaming properties) of hydrolysates are associated with molecular weight (MW), in which low-MW hydrolysate possessed the decreased viscosity with high solubility and could migrate to interface easily (Zhang et al., 2017).

Nowadays, ready-to-eat foods including healthy snacks are popular around the globe due to their availability and long storage time. However, during the processing of those snacks, the flavor and taste of the raw material can be depleted. Therefore, several kinds of flavorants have been introduced into those products to impart the desired flavor. Among them, food products with squid flavor produced by Bento, Lays, Pringles, etc. are widely popular in Southeast Asian countries. Squid flavor has been produced from the dried squid head, ink as well as mantle (Sukkhown et al., 2018). Squid fin can serve as potential raw material to produce flavorant, especially in the form of $\mathrm{PH}$. Currently, PH has been of great interest associated with their health-promotion due to the presence of bioactive peptides (Cao et al., 2009). Those peptides are well known for excellent antioxidant activities including free radical scavenging, metal chelating, etc., in which oxidative damage toward proteins and lipids could be limited (Singh, Idowu, et al., 2020; Sinthusamran et al., 2018). Moreover, oxidative stress, associated with free radicals generated in human-body caused several diseases, such as Alzheimer, hypertension, diabetes cancer, aging, etc. (Rahman, 2007). Therefore, the objective of the current study was to produce and characterize squid fin protein hydrolysate (SFPH) using alcalase. Moreover, amino acid (AAs) profile and volatile compounds in SFPH responsible for squid flavor were also determined.

\section{Materials and Methods}

\section{Raw Material, Enzyme and Chemicals}

Splendid squid (Loligo formosana) fins were obtained from Sea Wealth Frozen Food Co., Ltd., Songkhla, Thailand and transported to International Center of Excellence in Seafood Science and Innovation, Prince of Songkla University, Thailand in ice within $1 \mathrm{~h}$. The squid fin was then cut into small pieces $\left(1 \times 1 \mathrm{~cm}^{2}\right)$, placed in polyethylene bags, and stored at $-20{ }^{\circ} \mathrm{C}$ until use. The sample was stored for not more than 2 months.

Alcalase from Bacillus licheniformis (15 unit/mL) was obtained from Novozyme (Bagsvaerd, Denmark). All chemicals were of analytical grade and were purchased from Sigma Chemical Co. (St. Louis, MO, USA).
Sephadex ${ }^{\mathrm{TM}} \mathrm{G}-25$ and blue dextran were obtained from GE Healthcare (Uppsala, Sweden).

\section{Preparation of Squid Fin Protein Hydrolysate (SFPH)}

\section{Pre-treatment of Squid Fin}

Frozen splendid squid fin was thawed with running water and then bleached with $2 \% \mathrm{H}_{2} \mathrm{O}_{2}(\mathrm{w} / \mathrm{v})$ using a sample/solution ratio of $1: 10(\mathrm{w} / \mathrm{v})$ for $6 \mathrm{~h}$ with mild stirring using an overhead stirrer in a $4{ }^{\circ} \mathrm{C}$ walk-in room. $\mathrm{H}_{2} \mathrm{O}_{2}$ solution was changed twice after $3 \mathrm{~h}$. The bleached sample was rinsed three times with chilled water, followed by blending to obtain uniform homogenate.

\section{Hydrolysis of Bleached Squid Fin}

Blended bleached squid fin $(10 \mathrm{~g})$ was homogenized with $100 \mathrm{~mL}$ of distilled water for $2 \mathrm{~min}$ at 9,000 rpm using an IKA homogenizer (Labortechnik, Selangor, Malaysia). The mixture $(\mathrm{pH}$ 8) was preincubated at $60{ }^{\circ} \mathrm{C}$ for $15 \mathrm{~min}$ and then added with alcalase at $5,10,20$, and 30 units/g squid fin. At designated hydrolysis time $(5,10,15,20,30,40,60,90$, 120 , and $180 \mathrm{~min}), 1 \mathrm{~mL}$ of sample was taken and incubated in a water bath at $90{ }^{\circ} \mathrm{C}$ for $10 \mathrm{~min}$ to inactivate enzyme activity. The sample was used for the degree of hydrolysis (DH) determination using 2,4,6trinitrobenzene sulfonic acid (TNBS) solution (Benjakul \& Morrissey, 1997). In brief, hydrolysate samples with the appropriate dilution $(62.5 \mu \mathrm{L})$ were added with $1 \mathrm{~mL}$ of $0.2 \mathrm{M}$ phosphate buffer ( $\mathrm{pH} 8.2$ ) and $0.5 \mathrm{~mL}$ of $0.01 \%$ freshly prepared TNBS solution. The solution was mixed thoroughly and incubated at $50{ }^{\circ} \mathrm{C}$ in a water bath for 30 $\mathrm{min}$ in the dark. The reaction was terminated by adding $1 \mathrm{~mL}$ of $0.1 \mathrm{M}$ sodium sulphite. The mixtures were cooled at room temperature for $10 \mathrm{~min}$ in the dark. The absorbance was read at $420 \mathrm{~nm}$ using a UV-1601 spectrophotometer and $\alpha$-amino group was expressed in terms of L-leucine. The DH was computed as follows:

$$
\mathrm{DH}=\left(\mathrm{L}-\mathrm{L}_{0}\right) /\left(\mathrm{L}_{\max }-\mathrm{L}_{0}\right) \times 100
$$

where $L$ is the amount of $\alpha$-amino groups of hydrolysate sample. $L_{0}$ is the amount of $\alpha$-amino groups in the original sample. $L_{\max }$ is the total $\alpha$-amino groups in the sample obtained after acid hydrolysis $(6 \mathrm{M} \mathrm{HCl}$ at $130^{\circ} \mathrm{C}$ for $24 \mathrm{~h}$ ).

To prepare hydrolysates with several DHs (10$40 \%$ ), the amount of alcalase was calculated based on a linear relationship between $\mathrm{DH}$ and $\log _{10}$ (enzyme concentration). The hydrolysis was carried out as described previously at selected time of $60 \mathrm{~min}$. The obtained hydrolysates were centrifuged at $8000 \times \mathrm{g}$ for 15 min at $4{ }^{\circ} \mathrm{C}$. Then, the supernatants were freeze-dried using a freeze-dryer (CoolSafe 55, ScanLaf A/S, Lynge, Denmark) for $72 \mathrm{~h}$. All $\mathrm{PH}$ were further subjected to analyses. 


\section{Analyses}

Yield

The yield of SFPH with varying DHs was calculated using the following equations:

$$
\text { Yield }(\%, w b)=\frac{\text { weight of hydrolysate }(\mathrm{g})}{\text { weight of initial sample }(\mathrm{g})} \times 100
$$

Yield $(\%, \mathrm{db})=\frac{\text { weight of dry hydrolysate }(\mathrm{g})}{\text { weight of initial dry sample }(\mathrm{g})} \times 100$

where $w b$ is wet weight basis and $d b$ is dry weight basis.

\section{Proximate Compositions}

Squid fin and SFPH having different DHs were analyzed for moisture, protein, fat, and ash contents using the AOAC method (AOAC, 2002).

\section{Color}

Color parameters such as lightness/brightness $\left(L^{*}\right)$ redness/greenness $\left(a^{*}\right)$, yellowness/blueness $\left(b^{*}\right)$ and color difference $\left(\Delta E^{*}\right)$ were calculated according to the method of Temdee et al. (2021).

\section{Molecular Weight (MW) Distribution}

MW distribution of SFPHs was determined using a Sephadex $\mathrm{G} 25$ gel filtration column $(2.5 \times 50 \mathrm{~cm})$ following the method given by Sinthusamran et al. (2018).

\section{Solubility}

The percentage of solubility was determined by measuring the protein content with respect to the total proteins in the samples as described by Sinthusamran et al. (2018).

\section{Foaming Capacity (FC) and Foaming Stability (FS)}

FC of solutions were estimated by whipping $20 \mathrm{~mL}$ of the sample solutions $(2 \%, w / v)$ following the method of Phadtare et al. (2021). FS was measured by calculating the foam destruction within 60 min after whipping at room temperature.

\section{Antioxidant Activities}

ABTS and DPPH radical scavenging activities (RSA), ferric reducing antioxidant power (FRAP) and metal chelating activity of SFPH samples were determined as per the method of Sae-Leaw et al. (2016).
Amino Acid Profile, Bitterness Intensity, and Volatile Compounds in SFPH-40

\section{Amino Acid Profile}

The AAs composition of SFPH-40 powder was analyzed using AAs analyzer as per the procedure of Nilsuwan et al. (2021).

\section{Volatile Compounds}

The isolation and concentration of volatiles were accomplished using the headspace solid-phase microextraction (HS-SPME) method, followed by GC-MS analysis (Nilsuwan et al., 2021).

\section{Bitterness}

The bitterness of SFPH-40 at various levels $(0,1,2$, 3 , and $4 \% ; w / v)$ was examined by 11 trained panellists ( 6 male and 5 female) following the method of Idowu et al. (2019) with slight modifications.

\section{Statistical Analysis}

A completely randomized design (CRD) was used for the whole study and data were subjected to one-way analysis of variance (ANOVA). The differences between means were evaluated by Duncan's multiple range test using the SPSS statistic program (SPSS 11.0 for Windows, SPSS Inc., Chicago, IL, USA).

\section{Results and Discussion}

\section{Degree of Hydrolysis (DH)}

The change in DH of SFPH prepared using alcalase at different concentrations as function of hydrolysis time is shown in Figure $1 \mathrm{~A}$. DH was augmented with increasing enzyme concentrations and hydrolysis time. The highest $\mathrm{DH}$ was obtained when alcalase at 30 unit/g sample was used. The $\mathrm{DH}$ was increased rapidly within the first 20 min. Thereafter, gradual increase in $\mathrm{DH}$ was noticeable with further augmenting time up to $180 \mathrm{~min}$. Similar results were reported during the hydrolysis of proteins obtained from yellow stripe (Klompong et al., 2007) and salmon (Gbogouri et al., 2004). This was associated with diminishing substrate, product inhibition or autodigestion of alcalase during the prolonged period of hydrolysis (Klompong et al., 2007). Alcalase at 2.83, 9.59, 32.40, and 109.47 units/g sample was used to achieve $\mathrm{DH}$ of $10,20,30$, and $40 \%$ as determined by the linear relationship between $\mathrm{DH}$ and alcalase concentrations (data not shown) (Klompong et al., 2007). Based on preliminary work, hydrolysis using a higher concentration of alcalase resulted in a darker hydrolysate, possibly associated with dark color of alcalase used. Thus, only SFPHs with 10, 20, 30, and $40 \%$ DH were prepared. 

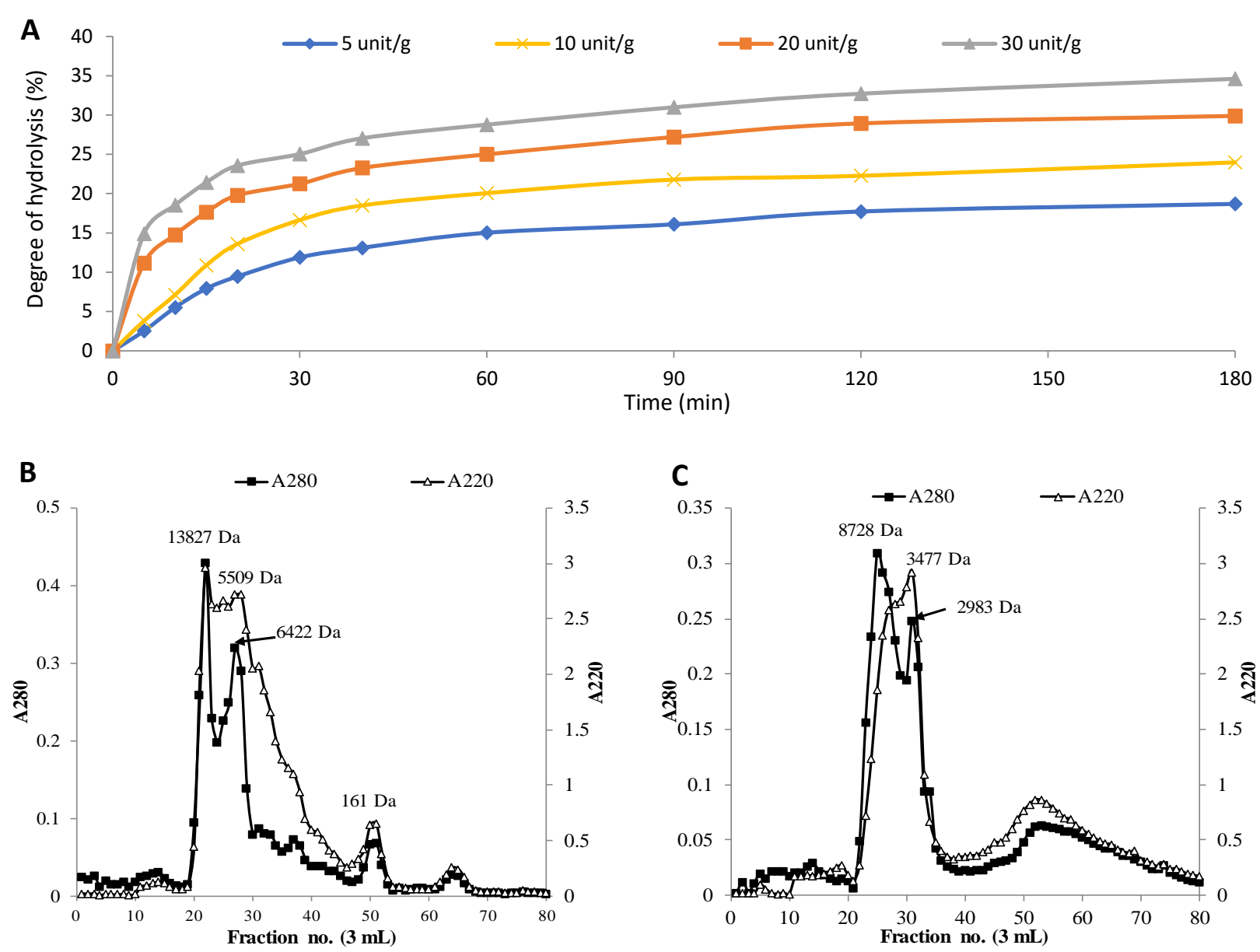

C
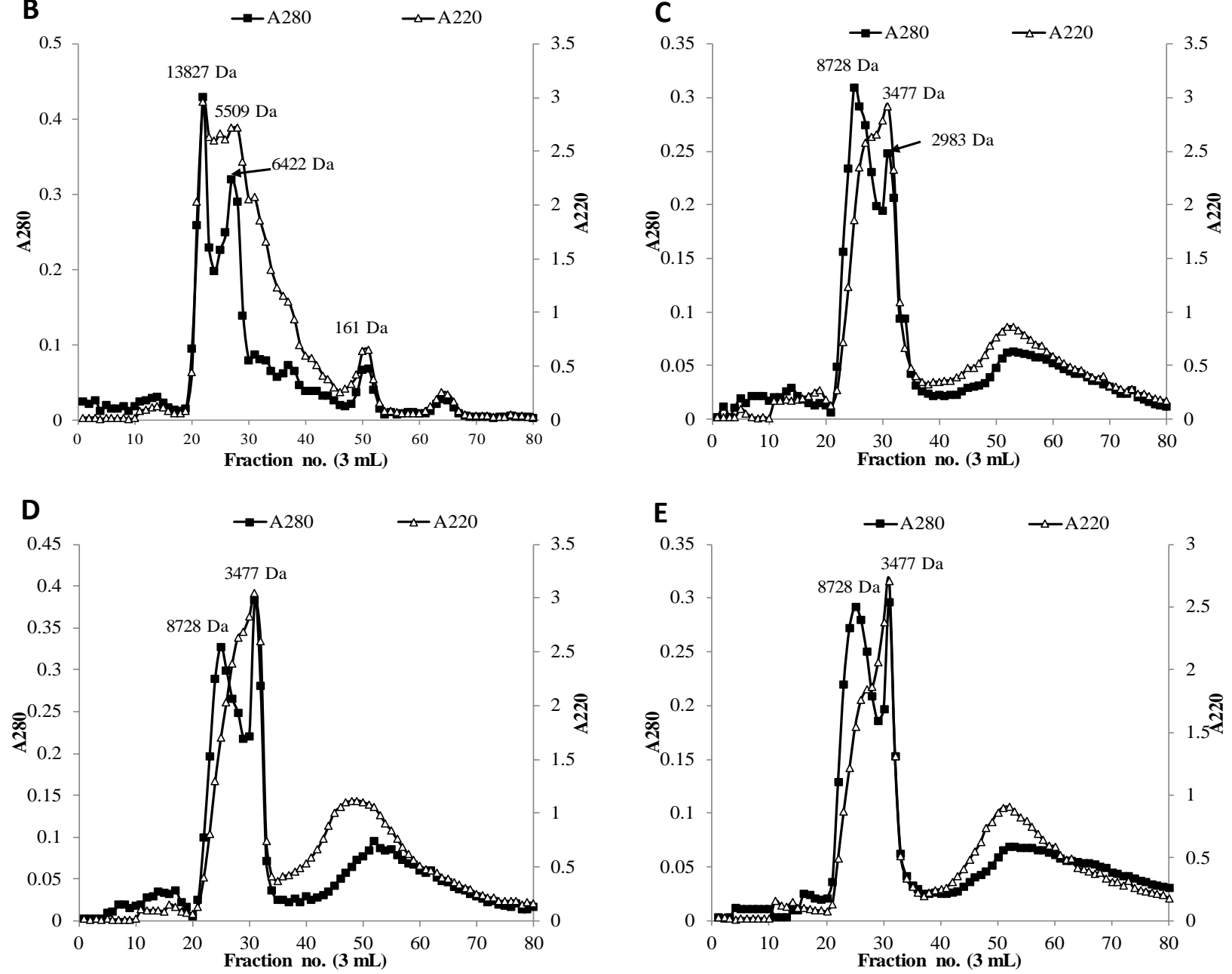

Figure 1. Degree of hydrolysis (DH) of splendid squid fin hydrolysates (SFPH) produced using alcalase at different concentrations as a function of time (A) and molecular weight distribution profile of SFPH with different $\mathrm{DHs}$ (B-E; 10-40\%, respectively).

\section{Proximate Compositions}

Proximate compositions of fresh splendid squid fin and SFPH having various DHs are shown in Table 1 . The raw squid fin had high content of proteins $(80.13 \%)$ followed by fat $(8.02 \%)$ and ash $(6.68 \%)$ (dry weight basis). On a wet weight basis, squid fin contained $85.25 \%$ water, $11.82 \%$ protein, $1.05 \%$ fat, and $0.98 \%$ ash. Similar chemical composition was found in the squid meat from the mantle, which contained $75-84 \%$ water, $13-22 \%$ protein, $0.1-2.7 \%$ fat, and $0-9-1.9 \%$ minerals (ash) (wet weight basis) (Sikorski \& Kołodziejska, 1986). For SFPH, no differences in protein and fat contents were noticed, irrespective of $\mathrm{DH}$ $(p<0.05)$. Nevertheless, ash content was reduced with increasing $\mathrm{DH}(\mathrm{p}<0.05)$. With dry weight basis, protein, fat, and ash contents of all SFPHs were in the range of 93.72-94.33\%, 2.65-3.16\%, and 1.10-1.73\%, respectively. All the SFPHs had high protein content, which might be associated with the solubilization of protein from the fins. SFPHs also showed high protein content than squid fin. Moreover, hydrolysis also 
removed insoluble substances, lipid, and inorganic components (metal ions) associated with the proteins. The lipid removal was also supported by the lower fat content in SFPH as compared to raw squid fin. Overall, $\mathrm{DH}$ did not affect the chemical composition of hydrolysates prepared by alcalase.

\section{Yield}

The yield of SFPH was increased with augmenting $\mathrm{DH}$, in which a higher amount of alcalase was used for hydrolysis (Table 1). The yields of 7.67, 8.27, 9.61, and $11.42 \%$ (wet weight basis) were found for SFPH-10, -20, -30 , and -40 samples, respectively. These results showed the positive relation between amount of alcalase used and amount of SFPH obtained. Based on dry matter, yields of $48.49,52.33,60.76$, and $72.21 \%$ were found for the aforementioned samples, respectively. Idowu et al. (2019) also reported increasing yield when $\mathrm{DH}$ of protein hydrolysate from salmon frames was increased. Alcalase was able to cleave peptide bonds inside the protein chain of squid fin during the hydrolysis process. A higher number of smaller peptides was generated and liberated into SFPH when a high amount of alcalase was used.

Color

Change in color values of SFPH with respect to the $\mathrm{DH}$ is shown in Table 2. The $L^{*}$ value was decreased with increasing $\mathrm{DH}$, indicating a reduction in the lightness of SFPH $(p<0.05)$, which was also supported by the augmenting $a^{*}$ and $b^{*}$ values, which represent redness and yellowness, respectively $(p<0.05)$. In general, hydrolysate powder having higher $\mathrm{DH}$ was yellowish brown in color. Similarly, Klompong et al. (2007) detected brownish color at higher $\mathrm{DH}(60 \%)$ of hydrolysate from round scad protein produced using flavourzyme. The reduction in lightness of SFPH powders was more likely due to the non-enzymatic browning (Maillard) reaction. This reaction occurs between amino group of peptides and carbonyl compounds. Moreover, pigments present in the alcalase as well as those remaining in squid fin might have contributed to the color of hydrolysates. The $\Delta E^{*}$ value was also increased with an upsurge in $\mathrm{DH}$, which suggested the color change. Hence, the varying color of SFPH was attributed to the composition and pigments of the raw material, type and amount of enzyme as well as and the hydrolysis condition.

\section{Molecular Weight (MW) Distribution}

Elution profiles of SFPH with various $\mathrm{DHs}$ are illustrated in Figure 1B-E. In general, $A_{220}$ has been used to monitor peptides, while $A_{280}$ indicates the peptides/proteins, primarily comprising aromatic amino acids (AAs) (Sinthusamran et al., 2018). All the samples had three major peaks at $A_{280}$, representing peptides comprising aromatic $\mathrm{AAs}$, which had $\mathrm{MW}$ in the range of 161-13827 Da. On the other hand, $\mathrm{A}_{220}$ had two major peaks (MW ranging from 161 to $5509 \mathrm{Da}$ ) for all samples except SFPH-10, which had an extra peak having MW of 13827 Da (Figure 1B). When DH was higher than 10\%,

Table 1. Proximate composition and yield of splendid squid fins and squid fin protein hydrolysate (SFPH) produced using alcalase with different degrees of hydrolysis.

\begin{tabular}{|c|c|c|c|c|c|}
\hline & Splendid squid fins & SFPH-10 & SFPH-20 & SFPH-30 & SFPH-40 \\
\hline Moisture & $85.25 \pm 0.16$ & $1.72 \pm 0.16^{\mathrm{b}}$ & $2.01 \pm 0.78^{b}$ & $5.33 \pm 0.18^{a}$ & $5.37 \pm 0.35^{\mathrm{a}}$ \\
\hline \multirow{2}{*}{ Protein } & $11.82 \pm 0.17$ & $91.61 \pm 1.55^{a}$ & $91.72 \pm 3.26^{a}$ & $89.00 \pm 1.98^{a}$ & $89.26 \pm 4.14^{a}$ \\
\hline & $(80.13 \pm 1.12)$ & $\left(93.72 \pm 0.56^{a}\right)$ & $\left(94.12 \pm 3.33^{a}\right)$ & $\left(94.01 \pm 1.14^{\mathrm{a}}\right)$ & $(94.33 \pm 4.37 \mathrm{a})$ \\
\hline \multirow{2}{*}{ Fat } & $1.05 \pm 0.27$ & $2.91 \pm 0.87^{a}$ & $2.80 \pm 0.84^{a}$ & $2.99 \pm 0.92^{\mathrm{a}}$ & $2.98 \pm 0.33^{a}$ \\
\hline & $(8.02 \pm 0.23)$ & $\left(2.96 \pm 0.89^{a}\right)$ & $\left(2.65 \pm 1.06^{a}\right)$ & $\left(3.16 \pm 0.97^{a}\right)$ & $\left(2.83 \pm 0.35^{a}\right)$ \\
\hline \multirow{2}{*}{ Ash } & $0.98 \pm 0.07$ & $1.65 \pm 0.05^{\mathrm{a}}$ & $1.50 \pm 0.31^{\mathrm{ab}}$ & $1.30 \pm 0.13^{b}$ & $1.05 \pm 0.27^{b}$ \\
\hline & $(6.68 \pm 0.49)$ & $\left(1.68 \pm 0.05^{a}\right)$ & $\left(1.63 \pm 0.32^{\mathrm{a}}\right)$ & $\left(1.37 \pm 0.14^{b}\right)$ & $\left(1.10 \pm 0.29^{b}\right)$ \\
\hline \multirow{2}{*}{ Yield } & \multirow{2}{*}{ 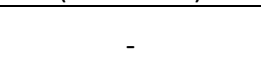 } & $7.67 \pm 0.12^{\mathrm{a}}$ & $8.27 \pm 0.12^{b}$ & $9.61 \pm 0.24^{c}$ & $11.42 \pm 0.13^{d}$ \\
\hline & & $\left(48.49 \pm 0.77^{a}\right)$ & $\left(52.33 \pm 0.73^{b}\right)$ & $\left(60.76 \pm 1.50^{c}\right)$ & $\left(72.21 \pm 0.82^{d}\right)$ \\
\hline
\end{tabular}

Values are presented as mean \pm SD $(n=3)$. Values are on wet weight basis, except in brackets, which is represented as dry weight basis. Different lowercase superscripts within the same row indicate significant difference $(p<0.05)$.

SFPH-10, SFPH-20, SFPH-30, SFPH-40: Squid fin protein hydrolysate (SFPH) powder with degree of hydrolysis of 10, 20, 30, and 40\%, respectively.

Table 2. Color, solubility, and foaming properties of squid fin protein hydrolysate (SFPH) produced using alcalase with different degrees of hydrolysis.

\begin{tabular}{|c|c|c|c|c|c|c|c|}
\hline \multirow{2}{*}{ Samples } & \multicolumn{4}{|c|}{ Color } & \multirow{2}{*}{$\begin{array}{c}\text { Solubility } \\
\text { (\%) }\end{array}$} & \multirow{2}{*}{$\begin{array}{c}\text { Foaming } \\
\text { capacity (\%) }\end{array}$} & \multirow{2}{*}{$\begin{array}{c}\text { Foaming } \\
\text { stability (\%) }\end{array}$} \\
\hline & $L^{*}$ & $a^{*}$ & $b^{*}$ & $\Delta E^{*}$ & & & \\
\hline SFPH-10 & $89.79 \pm 0.11^{\mathrm{a}}$ & $0.88 \pm 0.04^{c}$ & $10.62 \pm 0.13^{c}$ & $10.43 \pm 0.13^{c}$ & $89.80 \pm 1.67^{c}$ & $72.46 \pm 2.45^{d}$ & $31.78 \pm 2.52^{c}$ \\
\hline SFPH-20 & $88.84 \pm 0.09^{b}$ & $1.04 \pm 0.21^{c}$ & $10.57 \pm 0.52^{c}$ & $10.48 \pm 0.53^{c}$ & $93.65 \pm 0.43^{b}$ & $80.95 \pm 2.70^{c}$ & $34.92 \pm 3.26^{c}$ \\
\hline SFPH-30 & $87.30 \pm 0.21^{c}$ & $1.32 \pm 0.10^{\mathrm{b}}$ & $13.41 \pm 0.35^{b}$ & $13.61 \pm 0.34^{b}$ & $96.49 \pm 1.43^{a}$ & $85.98 \pm 1.36^{b}$ & $50.40 \pm 2.87^{b}$ \\
\hline SFPH-40 & $81.29 \pm 0.21^{d}$ & $4.20 \pm 0.24^{\mathrm{a}}$ & $21.15 \pm 0.45^{\mathrm{a}}$ & $23.37 \pm 0.54^{a}$ & $97.05 \pm 2.26^{a}$ & $105.29 \pm 1.95^{a}$ & $81.68 \pm 2.04^{\mathrm{a}}$ \\
\hline
\end{tabular}

Values are presented as mean \pm SD $(n=3)$.

Different lowercase superscripts within the same column indicate significant difference $(p<0.05)$. Caption: see Table 1 
the peak $\left(A_{280}\right)$ of peptides having MW of $13827 \mathrm{Da}$ disappeared. This coincided with the formation of another peak with MW of 8728 Da. Similarly, A220 showed a shift in the peak of MW 5509 to $3477 \mathrm{Da}$. The result suggested the hydrolysis of high $\mathrm{MW}$ proteins/peptide with increasing $\mathrm{DH}$, thus resulting in the formation of smaller proteins as well as peptides. This was advocated by increasing surface area of the peak of MW 161 Da monitored using both $A_{220}$ and $A_{280}$. The increase in DH (Figure 1A) of SFPH was in line with the upsurging peak area of fractions with low MW peptides. Sinthusamran et al. (2018) also noticed the varying MW profiles as influenced by $\mathrm{DH}$, which could be affected by the amount and type of enzyme as well as hydrolysis time.

\section{Solubility}

All samples showed $85-97 \%$ of solubility at neutral $\mathrm{pH}$ (Table 2). The lowest solubility was noticed in SFPH10 , followed by SFPH-20 sample $(p<0.05)$. The maximum solubility was noticed for SFPH-30 and SFPH-40 samples $(p<0.05)$, however both showed similar solubility $(p>0.05)$. PH from yellow stripe trevally meat produced using alcalase and flavourzyme with different DHs (5$25 \%$ ) also exhibited solubility higher than $85 \%$ (Klompong et al., 2007). Higher solubility of SFPH samples with higher $\mathrm{DH}$ is associated with the presence of smaller peptides having polar residues, which were capable of forming $\mathrm{H}$-bonds with water (Klompong et al., 2007). Hydrolysis has been known to alter molecular size as well as hydrophobicity, which directly influence the functional properties of resulting peptides (Singh \& Benjakul, 2019). Moreover, hydrophobicity/ hydrophilicity ratio or charged AAs also affect the solubility of PH (Gbogouri et al., 2004; Klompong et al., 2007). Hence, solubility of SFPH having different DHs is influenced by peptides size, hydrophobic-hydrophilic ratio, and charged AAs in the peptides.

\section{Foaming Properties}

Foaming capacity (FC) and foaming stability (FS) of SFPH powders with different DHs are shown in Table 2. FC was increased (72-105\%) with an upsurge of $\mathrm{DH}$ $(p<0.05)$, in which the highest FC was noticed for SFPH$40(105.29 \%)(p<0.05)$. In general, foaming ability of proteins is related to their ability to form film at the interface of air and water (Singh et al., 2017). During whipping, protein, that rapidly adsorbs at the interface, undergoes unfolding as well as molecular reorganization, thus improving foaming properties more effectively than protein that adsorbs slowly and resists unfolding at the interface of air and water (Zayas, 1997). Bao et al. (2017) also reported increasing FC of egg yolk hydrolysates with increasing $\mathrm{DH}$. With increasing $\mathrm{DH}$, peptides, which had smaller size, were able to relocate to the interfacial film instantly and occupy the interface more potentially than other having larger size. Similarly, FS of SFPH was upsurged with increasing $\mathrm{DH}(\mathrm{p}<0.05)$. Nevertheless, SFPH-10 and SFPH-20 had similar FS ( $p>0.05$ ). Generally, enzymatic hydrolysis reduced MW (Figure $1 \mathrm{~B}-\mathrm{E})$, thereby enhancing the solubility and exposing hydrophobic domains. Since peptides in SFPH40 rapidly migrated to interface and could arrange themselves, in the way which stronger film could entrap air bubble potentially. As a consequence, the foam was stable as indicated by the highest foaming stability. On contrary, foaming properties of hydrolysate obtained from yellow stripe trevally were reduced with increasing DH (Klompong et al., 2007). This was more likely due to the difference in size and charge of peptides, which could be affected by the hydrolyzing enzymes, time, substrate, etc. (Klompong et al., 2007; Zayas, 1997).

\section{Antioxidant Activities}

Antioxidant activities of SFPH samples were measured by ABTS, DPPH, FRAP, and metal chelating assays as shown in Table 3. ABTS-RSA of SFPH was increased with augmenting $\mathrm{DH}$ and the highest activity was found for SFPH-30 and SFPH-40 samples $(p<0.05)$, but both samples showed similar activity $(p>0.05)$. Alcalase with a broad specificity for peptide bonds produced short-chain peptides, which could scavenge ABTS radicals. Similarly, upsurged DPPH-RSA was observed as DH was increased up to $30 \%$ ( $p>0.05)$. When $\mathrm{DH}$ reached $40 \%$, lower activity was noticed $(p<0.05)$. Therefore, peptides in hydrolysates with varying $\mathrm{DHs}$ might scavenge ABTS and DPPH radicals with different modes of action. Usually, peptides/proteins present in hydrolysate can act as $\mathrm{H}$-donors, which convert radicals to more stable products and inhibit radical chain reaction (Khantaphant \& Benjakul, 2008; Sinthusamran et al., 2018). ABTS assay determines the H-donating ability of compounds in aqueous phase (Singh, Idowu, et al., 2020). With high ABTS-RSA, it was postulated that SFPH mainly contained hydrophilic components. For DPPH-RSA, it is generally used to determine the $\mathrm{H}$ donating ability of a compound in a lipophilic system (Wu, Chen, \& Shiau, 2003). The result suggested that the hydrolysates at higher $\mathrm{DH}$ might contain more electron

Table 3. Antioxidant activities of squid fin protein hydrolysate (SFPH) produced using alcalase with different degrees of hydrolysis.

\begin{tabular}{lcccc}
\hline Antioxidant assays & SFPH-10 & SFPH-20 & SFPH-30 & SFPH- 40 \\
\hline ABTS $(\mu$ mol TE/g sample) & $862.15 \pm 93.91^{\mathrm{c}}$ & $1,074.64 \pm 98.31^{\mathrm{b}}$ & $1,219.10 \pm 83.58^{\mathrm{a}}$ & $1,213.59 \pm 37.79^{\mathrm{a}}$ \\
DPPH $(\mu \mathrm{mol}$ TE/g sample) & $3.22 \pm 0.11^{\mathrm{a}}$ & $3.33 \pm 0.20 \mathrm{~b}^{\mathrm{a}}$ & $3.57 \pm 0.13^{\mathrm{a}}$ & $2.79 \pm 0.07^{\mathrm{b}}$ \\
FRAP $(\mu \mathrm{mol}$ TE/g sample) & $22.54 \pm 1.74^{\mathrm{d}}$ & $26.63 \pm 2.46^{\mathrm{c}}$ & $29.19 \pm 0.75^{\mathrm{b}}$ & $32.98 \pm 1.35^{\mathrm{a}}$ \\
Metal chelating activity $(\mu \mathrm{mol}$ EDTA/g sample) & $1.05 \pm 0.01^{\mathrm{a}}$ & $1.08 \pm 0.03^{\mathrm{a}}$ & $0.85 \pm 0.08^{\mathrm{b}}$ & $0.61 \pm 0.03^{\mathrm{c}}$ \\
\hline Vat
\end{tabular}

Values are presented as mean $\pm \mathrm{SD}(n=3)$.

Different lowercase superscripts within the same row indicate significant difference $(p<0.05)$. Caption: see table 1. 
donors in the form of hydrophilic AAs or peptides, which resulted in a lower capacity to scavenge lipophilic DPPH radicals. Similarly, Sinthusamran et al. (2018) observed lower DPPH-RSA of PH from Pacific white shrimp cephalothorax at higher $\mathrm{DH}$.

FRAP activity was increased by augmenting $\mathrm{DH}$ $(p<0.05)$ (Table 3$)$. Generally, reducing capacity is determined by its potential to donate an electron to a free radical (Wang et al., 2008). FRAP is commonly used to measure the capacity of a substance to reduce TPTZFe(III) complex to TPTZ-Fe(II) complex (Sae-Leaw et al., 2016). The higher FRAP activity, especially at high DH was more likely due to the electron donation to the free radical, which prevents or retards propagation (Sinthusamran et al., 2018). The result of the study agreed with hydrolysates produced from gelatin and protein isolate extracted from splendid squid prepared using proteases from shrimp hepatopancreas (Hamzeh, Benjakul, \& Senphan, 2016). Conversely, the lower FRAP activity of $\mathrm{PH}$ from yellow stripe trevally produced using alcalase was obtained at higher DH (Klompong et al., 2007). This might be governed by different peptides produced.

Based on metal chelating activity, SFPH-10 and SFPH-20 exhibited the highest activity $(p<0.05)$. However, both samples had similar values $(p>0.05)$ (Table 3). On the other hand, with further increase in $\mathrm{DH}$ to $40 \%$, lower activity was noticed $(p<0.05)$. In general, complex formed between ferrozine and $\mathrm{Fe}^{2+}$ ion is disrupted in the presence of the chelating agent, resulting in the decrease in color formation (Thiansilakul et al., 2007). The lower metal chelating activity at higher $\mathrm{DH}$ was mainly due to the alternation in structure and sequence of peptide chains. Hamzeh et al. (2016) also reported decreasing metal chelating activity of splendid squid gelatin hydrolysate with an increase in $\mathrm{DH}$ to $30 \%$. However, no difference in metal chelating activity was noticed for hydrolysates from splendid squid mantle protein isolate having $\mathrm{DH}$ of $10-30 \%$ (Hamzeh et al., 2016).

Therefore, DH, enzymes used, raw material, etc. influenced the antioxidant activities of $\mathrm{PH}$ (Klompong et al., 2008). Based on yield, solubility, foaming properties, and antioxidant activities, SFPH-40 sample was selected for further characterization.

\section{Amino Acid Profile, Bitterness Intensity, and Volatile Compounds of SFPH-40}

\section{Amino Acid Profile}

AAs profile of SFPH-40 sample is shown in Table 4. Glutamic acid/glutamine (10.60 g/100 g sample) was the most abundant AAs in SFPH-40 followed by lysine (7.58 g/100 g sample) and aspartic acid/asparagine ( $7.26 \mathrm{~g} / 100 \mathrm{~g})$. Leucine $(6.07 \mathrm{~g} / 100 \mathrm{~g}$ sample) was also found at a high concentration along with glycine (5.94 $\mathrm{g} / 100 \mathrm{~g}$ sample). The SFPH-40 had a favorable EAA/NEAA ratio $(0.70)$, which was higher than that of muscle proteins $(0.60)$ as reported by Iwasaki and

Table 4. Amino acid composition of squid fin protein hydrolysate (SFPH) produced using alcalase having $40 \%$ degree of hydrolysis.

\begin{tabular}{|c|c|}
\hline Amino acids (g/100 g sample) & SFPH-40 \\
\hline L-Alanine & $4.01 \pm 0.11$ \\
\hline L-Arginine & $5.94 \pm 0.21$ \\
\hline Aspartic acid/asparagine & $7.26 \pm 0.32$ \\
\hline Cystine & ND \\
\hline Glutamic acid/glutamine & $10.60 \pm 0.47$ \\
\hline Glycine & $5.94 \pm 0.36$ \\
\hline Histidine & $3.60 \pm 0.10$ \\
\hline Isoleucine & $2.58 \pm 0.08$ \\
\hline Leucine & $6.07 \pm 0.36$ \\
\hline Lysine & $7.58 \pm 0.35$ \\
\hline Hydroxylysine & $0.28 \pm 0.00$ \\
\hline Methionine & $1.26 \pm 0.01$ \\
\hline Phenylalanine & $2.50 \pm 0.02$ \\
\hline Hydroxyproline & $1.24 \pm 0.01$ \\
\hline Proline & $3.73 \pm 0.05$ \\
\hline Serine & $3.35 \pm 0.06$ \\
\hline Threonine & $3.68 \pm 0.04$ \\
\hline Tryptophan & $0.20 \pm 0.00$ \\
\hline Tyrosine & $1.55 \pm 0.00$ \\
\hline Valine & $2.78 \pm 0.01$ \\
\hline Essential amino acids (EAA) & $30.53 \pm 2.03$ \\
\hline Non-essential amino acids (NEAA) & $43.62 \pm 3.63$ \\
\hline EAA/NEAA ratio & 0.70 \\
\hline Polar to non-polar ratio (P-value) & $1.13 \pm 0.00$ \\
\hline Hydrophobic amino acids & $29.07 \pm 2.96$ \\
\hline Average hydrophobicity & $1064.14 \pm 8.06$ \\
\hline Frequency of nonpolar side chains (NPS) & $0.35 \pm 0.00$ \\
\hline
\end{tabular}


Harada (1985). The total hydrophobic AAs in SFPH-40 were $29.07 \mathrm{~g} / 100 \mathrm{~g}$. Normally, hydrophobic AAs are responsible for the bitterness of $\mathrm{PH}$ (Sinthusamran et al., 2020).

Polar to non-polar side chain ratio (P-value), frequency of non-polar side chains (NPS), and average hydrophobicity $(\mathrm{H} \Phi)$ of SFPH-40 were measured from the AAs composition following the calculations given by Bigelow (1967). In general, the fibrous proteins such as collagen, elastin, tropomyosin, cilia, etc. from various sources have NPS and P-value, and $H \Phi$ in the range of $0.018-41,0.09-2.14$, and 440-1120, respectively (Bigelow, 1967; Tristram \& Smith, 1963). Patil and Benjakul (2017) reported that the albumin from coconut milk proteins with high P-value (2.28) had lower NPS (0.21) and $H \Phi(780.23)$ values. On the other hand, globulin with low P-value (1.69) showed higher NPS (0.29) and $H \Phi(879.42)$. In current study, P-value, NPS, and $\mathrm{H} \Phi$ of SFPH-40 were 1.13, 0.35, and 1064.14, respectively, which were higher than the average values of various fibrous proteins as well as albumin and globulin fractions of the coconut milk proteins (except P-value). Using 150 proteins, Bigelow (1967) observed that P-value did not always show relationship with NPS and $H \Phi$ values. Therefore, balance between hydrophobic and hydrophilic parts of SFPH-40 determined solubility and foaming properties, which were related with P-value, NPS, and HФ values.

\section{Bitterness}

The bitterness score was directly proportional to the concentration of SFPH-40 sample, in which SFPH-40 sample at $1 \%(w / v)$ showed the lowest bitterness $(p<0.05)$. The bitterness scores of SFPH-40 sample at concentrations of $1,2,3$, and $4 \%(w / v)$ were $4.36,8.55$, 13.64, 14.91, respectively $(p<0.05)$. In general, hydrolysis exposes hidden hydrophobic AAs located inside globular protein, thus causing bitterness (Singh, Idowu, et al., 2020). In general, bitterness of PH is affected by the structure of peptides (Kim \& Li-Chan, 2006). The bulky hydrophobic AAs at the both C- and Nterminal in di- and tri-peptides caused bitterness, whereas bulky-hydrophobic groups either in the presence or absence basic-AAs at the C-terminal and bulky basic-AAs at the N-terminal in peptides larger than tetrapeptides are known for bitterness (Kim \& Li-Chan, 2006). The bulky-hydrophobic groups of hydrophobic AAs and tyrosine at C-terminal in peptides were able to bind with taste bud and cause bitterness (Idowu et al., 2019). The hydrolysate with higher hydrophobic AAs had enhanced sensation of the bitter taste. Moreover, proline localized internally in the peptide chain contributed to bitterness (Idowu et al., 2019). The result was supported by high P-value and $\mathrm{H} \Phi$ (Table 4). In addition, bitterness scores are affected by $\mathrm{DH}$, number of carbons inside the chain, especially for branchedchain AAs, and their concentration (Yarnpakdee et al., 2015). Therefore, an appropriate concentration of SFPH-
40 must be considered for the supplementation in various food products to avoid bitterness perceived by consumers.

\section{Volatile Compounds}

Volatile compounds in SFPH-40 sample are listed in Table 5. Various classes of chemicals were identified as follows: 7 aldehydes, 2 alcohols, 2 amides, 2 alkanes, 1 alkene, 3 aromatic, 7 carboxylic acids, and 7 ketones. Aldehydes are considered as most predominant volatile secondary oxidation products (SOPs) in SFPH-40 sample. The formation of aldehydes indicates lipid oxidation taken place in foods. Due to their low odor threshold value, they might result in off-odor and off-flavor (Nilsuwan et al., 2021). Various kinds of aldehydes such as hexanal, octanal, nonanal, pentanal, etc. were generated during oxidation (Ross \& Smith, 2006). Among all aldehyde compounds in SFPH-40 sample, butanal, 3-methyl- was highest in abundance followed by propanal, butanal, hexanal, benzaldehyde, and 2propenal, respectively (Table 5), which might be oxidation products of unsaturated fatty acid. The 3methyl-butanal showed green, fruity, nutty, cheese or sweat odors, which is found in Malaysian fish sauce (Mohamed et al., 2012). Cui et al. (2020) found 14 major aldehydes of low threshold value in cooked squid, which contributed to the flavor in cooked squid. During the enzymatic process, some lipids were oxidized and Strecker degradation of AAs occurred (Tan et al., 2018). The branched alcohol compounds namely, 2-penten-1ol and 1,5-octadien-3-ol were found in SFPH-40 sample and might produce aroma in SFPH-40 owing to their low threshold value as compared to short and long straight chain alcohols. 8-carbon alcohols are known to be present in all species of fish (Nagarajan et al., 2015). The unsaturated alcohol might be generated from n-3 and n6 polyunsaturated fatty acids. Alcohols in SFPH- 40 could serve as flavoring agent in various products such as soups and sauces. Two furan compounds, namely 3methyl-furan and 2-ethyl-furan were decomposed from $12-, \quad 14-$, and 16-hydroperoxide of linolenate, eicosapentaenoate and docosahexaenoate, respectively. Those compounds further produced conjugated diene radical through $\beta$-cleavage and reacted with oxygen to produce a vinyl hydroperoxide (Yarnpakdee et al., 2012). Moreover, breakdown of vinyl hydroperoxide through loss of hydroxyl radicals formed alkoxyl radicals, which were crystallized to furan (Maqsood \& Benjakul, 2011). Nevertheless, their contributions to SFPH-40 odor/flavor may be insignificant due to their low concentrations and high threshold values. Carboxylic acids were identified in SFPH-40 and might be formed from chemical and enzymatic oxidation of aldehydes. Moreover, Nterminal of peptide might consist of several alkyl carboxylic acids, which act as a blocking group, thus regulating various biological activities (Moscarello et al., 1992). Ketones significantly contributed to flavor of fish 
products due to their low threshold value. Seven types of ketones were identified and quantified in SFPH-40 (Table 5), in which 1-Penten-3-one was most abundant, which is a fish, garlic, and mustard tasting compound. The 2,3-pentanedione was also present in sufficient amount, which is known to render the intense odorant in squid (Shahidi, 1998). Moreover, other compounds such as aliphatic hydrocarbons including, 2-methyl-1,3butadiene, oxybis-methane, and 3-methyl pentane along with toluene and amides were also identified. Hydrocarbons present in SFPH-40 had less impact on the overall flavor of foods because of their high aroma thresholds (Wang et al., 2010). Since there were several volatiles in SFPH-40, those compounds could synergistically contribute to the flavor. Some of volatile compounds associated with specific flavors might be lost during the preparation of hydrolysate. Nevertheless, the major contributors to unique squid flavor should be further investigated.

\section{Conclusions}

Splendid squid fin protein hydrolysate (SFPH) prepared using alcalase with $40 \% \mathrm{DH}$ (SFPH-40) had the highest relative solubility, foaming capacity, and foaming stability. All SFPH possessed antioxidant activities, which varied, depending on the DH. The SFPH40 was rich in essential AAs as well as hydrophobic AAs. The bitterness of the SFPH-40 was increased when its concentration was increased. Aldehydes, alcohols, carboxylic acids, and ketones were the abundant volatile compounds in the SFPH-40 sample. Overall, SFPH-40 at appropriate concentration could be used to improve the nutritional, functional, and squid flavor of various food products, in which further study is required.

\section{Ethical Statement}

Ethical approval is not required for this study.

\section{Author Contribution}

Conceptualization, A.S. and S.B.; methodology, A.S. and G.A.U.P.; software, A.S.; validation, A.S., S.B. and A.J.; formal analysis, A.S.; investigation, A.S., A.J. and G.A.U.P.; resources, S.B.; data curation, S.B.; writingoriginal draft preparation, A.S.; writing-review and editing, S.B., A.F.Y., and H.H.; visualization, A.S.; H.H., and A.F.Y.; supervision, S.B.; project administration, S.B.; funding acquisition, S.B. All authors have read and agreed to the published version of the manuscript.

Table 5. Volatile compounds of squid fin protein hydrolysate (SFPH) produced using alcalase having $40 \%$ degree of hydrolysis

\begin{tabular}{|c|c|c|}
\hline Classes & Compounds & SFPH-40 \\
\hline \multirow{7}{*}{ Aldehyde } & Benzaldehyde & 1.02 \\
\hline & Butanal & 1.31 \\
\hline & Butanal, 3-methyl- & 2.65 \\
\hline & Hexanal & 1.06 \\
\hline & (E)-4-Oxohex-2-enal & 0.78 \\
\hline & Propanal & 1.64 \\
\hline & 2-Propenal & 0.81 \\
\hline \multirow{2}{*}{ Alcohol } & 2-Penten-1-ol, (Z)- & 1.59 \\
\hline & 1,5-Octadien-3-ol, (Z)- & 1.19 \\
\hline \multirow{2}{*}{ Heterocyclic } & Furan, 3-methyl- & 0.70 \\
\hline & Furan, 2-ethyl- & 1.18 \\
\hline \multirow{7}{*}{ Carboxylic acid } & Acetic acid & 4.87 \\
\hline & Benzoic acid & 0.24 \\
\hline & Butanoic acid & 0.32 \\
\hline & Hexanoic acid & 0.61 \\
\hline & Pentanoic acid & 0.62 \\
\hline & Propanoic acid & 6.11 \\
\hline & Sorbic Acid & 0.34 \\
\hline \multirow{7}{*}{ Ketone } & 3-Buten-2-one & 0.37 \\
\hline & 2-Butanone & 1.50 \\
\hline & 2-Nonanone & 0.46 \\
\hline & 2-Pentanone & 1.89 \\
\hline & 1-Penten-3-one & 4.69 \\
\hline & 2,3-Pentanedione & 1.17 \\
\hline & 1-Phenyl-ethanone & 1.49 \\
\hline \multirow{6}{*}{ Other compounds } & Toluene & 0.25 \\
\hline & 1,3-Butadiene, 2-methyl- & 0.24 \\
\hline & Acetamide & 0.42 \\
\hline & Propanamide & 0.59 \\
\hline & Methane, oxybis- & 0.38 \\
\hline & Pentane, 3-methyl- & 0.30 \\
\hline
\end{tabular}

Values are expressed as abundance $\left(\times 10^{8}\right)$. SFPH-40: squid fin protein hydrolysates of degree of hydrolysis of $40 \%$. 


\section{Conflict of Interest}

All authors declare that there is no conflict of interest.

\section{Acknowledgement and Funding}

Chair professor grant (P-20-52297) from National Science and Technology Development Agency (Grant P20-52297) and Prachayacharn program from Prince of Songkla University (AGR6402088N) were acknowledged.

\section{References}

AOAC. (2002). Official Methods of Analysis. In Association of Official Analytical Chemists (16 ed.). Washington, DC.

Bao, Z.-J., Y. Zhao, X.-Y. Wang, and Y.-J. Chi. (2017). Effects of degree of hydrolysis $(\mathrm{DH})$ on the functional properties of egg yolk hydrolysate with alcalase. Journal of food science and technology 54: 669-678. http://doi.org/10.1007/s13197-017-2504-0

Benjakul, S., and M.T. Morrissey. (1997). Protein hydrolysates from Pacific whiting solid wastes. Journal of Agricultural and Food Chemistry 45: 3423-3430.

Bigelow, C.C. (1967). On the average hydrophobicity of proteins and the relation between it and protein structure. Journal of Theoretical Biology 16: 187-211.

Cao, W., C. Zhang, P. Hong, H. Ji, J. Hao, and J. Zhang. (2009). Autolysis of shrimp head by gradual temperature and nutritional quality of the resulting hydrolysate. LWTFood Science and Technology 42: 244-249.

Cui, Z., H. Yan, T. Manoli, H. Mo, H. Li, and H. Zhang. (2020). Changes in the volatile components of squid (IIlex argentinus) for different cooking methods via headspace-gas chromatography-ion mobility spectrometry. Food Science and Nutrition 8: 5748-5762. https://doi.org/10.1002/fsn3.1877

Gbogouri, G., M. Linder, J. Fanni, and M. Parmentier. (2004). Influence of hydrolysis degree on the functional properties of salmon byproducts hydrolysates. Journal of Food Science 69: C615-C622.

Hamzeh, A., S. Benjakul, and T. Senphan. (2016). Comparative study on antioxidant activity of hydrolysates from splendid squid (Loligo formosana) gelatin and protein isolate prepared using protease from hepatopancreas of Pacific white shrimp (Litopenaeus vannamei). Journal of food science and technology 53: 3615-3623. http://doi.org/10.1007/s13197-016-2348-z

Idowu, A.T., S. Benjakul, S. Sinthusamran, P. Sookchoo, and H. Kishimura. (2019). Protein hydrolysate from salmon frames: Production, characteristics and antioxidative activity. Journal of Food Biochemistry 43: e12734. http://doi.org/10.1111/jfbc.12734

Iwasaki, M., and R. Harada. (1985). Proximate and amino acid composition of the roe and muscle of selected marine species. Journal of Food Science 50: 1585-1587.

Khantaphant, S., and S. Benjakul. (2008). Comparative study on the proteases from fish pyloric caeca and the use for production of gelatin hydrolysate with antioxidative activity. Comparative Biochemistry and Physiology Part B: Biochemistry and Molecular Biology 151: 410-419.

Kim, H.O., and E.C.Y. Li-Chan. (2006). Quantitative structureactivity relationship study of bitter peptides. Journal of
Agricultural and Food Chemistry 54: 10102-10111.

Klompong, V., S. Benjakul, D. Kantachote, and F. Shahidi. (2007). Antioxidative activity and functional properties of protein hydrolysate of yellow stripe trevally (Selaroides leptolepis) as influenced by the degree of hydrolysis and enzyme type. Food Chemistry 102: 1317 1327.

Klompong, V., S. Benjakul, D. Kantachote, K.D. Hayes and F. Shahidi. (2008). Comparative study on antioxidative activity of yellow stripe trevally protein hydrolystae produced from Alcase and Flavourzyme. International Journal of Food Science and Technology 43: 1019-1026.

Liu, Q., B. Kong, Y.L. Xiong, and X. Xia. (2010). Antioxidant activity and functional properties of porcine plasma protein hydrolysate as influenced by the degree of hydrolysis. Food Chemistry 118: 403-410.

Maqsood, S., and S. Benjakul. (2011). Comparative studies on molecular changes and pro-oxidative activity of haemoglobin from different fish species as influenced by pH. Food Chemistry 124: 875-883.

Mohamed, H.N., Y.C. Man, S. Mustafa, and Y.A. Manap. (2012). Tentative identification of volatile flavor compounds in commercial budu, a Malaysian fish sauce, using GC-MS. Molecules 17: 5062-5080.

Moscarello, M., H. Pang, C.R. Pace-Asciak, and D.D. Wood. (1992). The $\mathrm{N}$ terminus of human myelin basic protein consists of C2, C4, C6, and C8 alkyl carboxylic acids. Journal of Biological Chemistry 267: 9779-9782.

Nagarajan, M., S. Benjakul, T. Prodpran, and P. Songtipya. (2015). Effects of bio-nanocomposite films from tilapia and squid skin gelatins incorporated with ethanolic extract from coconut husk on storage stability of mackerel meat powder. Food Packaging and Shelf Life 6: 42-52.

Nilsuwan, K., K. Chantakun, L. Chotphruethipong, and S. Benjakul. (2021). Development of Hydrolysis and Defatting Processes for Production of Lowered Fishy Odor Hydrolyzed Collagen from Fatty Skin of Sockeye Salmon (Oncorhynchus nerka). Foods 10: 2257.

Patil, U., and S. Benjakul. (2017). Characteristics of albumin and globulin from coconut meat and their role in emulsion stability without and with proteolysis. Food hydrocolloids 69: 220-228.

Phadtare, M.C., Ranveer, R.C., Rathod, N.B., Sharangdhar, S.T., Swami, S.B., Vartak, V.R., Koli, J.M., \& Pujari, K.H. (2021). Extraction, characterization and utilization of fish protein concentrate. Aquatic Food Studies, 1: AFS47. http://doi.org/10.4194/AFS47

Rahman, K. (2007). Studies on free radicals, antioxidants, and co-factors. Clinical Interventions in Aging 2: 219.

Ross, C.F., and D.M. Smith. (2006). Use of volatiles as indicators of lipid oxidation in muscle foods. Comprehensive Reviews in Food Science and Food Safety 5: 18-25.

Sae-Leaw, T., Y.C. O'Callaghan, S. Benjakul, and N.M. O'Brien. 2016. Antioxidant activities and selected characteristics of gelatin hydrolysates from seabass (Lates calcarifer) skin as affected by production processes. Journal of food science and technology 53: 197-208. http://doi.org/10.1007/s13197-015-1989-7

Shahidi, F. (1998). Flavor of meat, meat products and seafoods (2 ed.). London, UK: Blackie Academic and Professional.

Shahidi, F. (2006). Maximising the value of marine by-products. Sawston, United Kingdom: Woodhead Publishing.

Sikorski, Z.E., and I. Kołodziejska. (1986). The composition and properties of squid meat. Food Chemistry 20: 213-224. 
Singh, A., and S. Benjakul. (2019). Effect of partial enzymatic hydrolysis on physicochemical and foaming properties of ovary from squid Loligo formosana. Waste and Biomass Valorization 10: 3351-3361. http://doi.org/10.1007/s12649-018-0348-0

Singh, A., S. Benjakul, and H. Kishimura. (2017). Characteristics and functional properties of ovary from squid Loligo Formosana. Journal of Aquatic Food Product Technology 26: 1083-1092. doi:10.1080/10498850.2017.1376026

Singh, A., A.T. Idowu, S. Benjakul, H. Kishimura, R. E. Aluko, and Y. Kumagai. (2020). Debittering of salmon (Salmo salar) frame protein hydrolysate using 2-butanol in combination with $\beta$-cyclodextrin: Impact on some physicochemical characteristics and antioxidant activities. Food Chemistry 321: 126686.

Singh, A., A. Mittal, and S. Benjakul. (2020). Full utilization of squid meat and its processing by-products: revisit. Food Reviews Internationa/1-25, http://doi.org/10.1080/87559129.2020.1734611

Sinthusamran, S., S. Benjakul, K. Kijroongrojana, T. Prodpran, and H. Kishimura. (2018). Protein hydrolysates from Pacific white shrimp cephalothorax manufactured with different processes: compositions, characteristics and antioxidative activity. Waste and Biomass Valorization 11: 1657-1670. http://doi.org/10.1007/s12649-018-0517-1

Sinthusamran, S., A.T. Idowu, S. Benjakul, T. Prodpran, A.F. Yesilsu, and H. Kishimura. (2020). Effect of proteases and alcohols used for debittering on characteristics and antioxidative activity of protein hydrolysate from salmon frames. Journal of Food Science and Technology 57: 473483. http://doi.org/10.1007/s13197-019-04075-z

Sukkhown, P., K. Jangchud, Y. Lorjaroenphon, and T. Pirak. (2018). Flavored-functional protein hydrolysates from enzymatic hydrolysis of dried squid by-products: Effect of drying method. Food Hydrocolloids 76: 103-112. doi:

Tan, X.Y., L.B. Qi, F.J. Fan, Z.X. Guo, Z.Y. Wang, W. Song, and M. Du. (2018). Analysis of volatile compounds and nutritional properties of enzymatic hydrolysate of protein from cod bone. Food Chemistry 264: 350-357.

Temdee, W., Benjakul, S., Surasani, V.K.R., \& Singh, A. (2021). Effects of ethanolic extract of kiam wood/cashew bark and commercial phenolic compounds oxidized under alkaline condition on gel property of gelatin from cuttlefish skin. Aquatic Food Studies 1(1), AFS14.
http://doi.org/10.4194/AFS-14

Thiansilakul, Y., S. Benjakul, and F. Shahidi. (2007). Antioxidative activity of protein hydrolysate from round scad muscle using alcalase and flavourzyme. Journal of Food Biochemistry 31: 266-287.

Tristram, G.R., and R.H. Smith. (1963). The amino acid composition of some purified proteins. Advances in Protein Chemistry 18: 227-318. http://doi.org/10.1016/s0065-3233(08)60270-3

Wang, H.-H., Z.-Y. Dai, R.-H. Yang, H.-J. Zhao, and L.-P. Weng. (2010). Comparison of the flavor components between the squid and the smoked squid by GC-MS. Food Research and Development 11: 043.

Wang, H., X.D. Gao, G. C. Zhou, L. Cai, and W.B. Yao. (2008). In vitro and in vivo antioxidant activity of aqueous extract from Choerospondias axillaris fruit. Food Chemistry 106: 888-895.

Wu, H.-C., H.-M. Chen, and C.-Y. Shiau. (2003). Free amino acids and peptides as related to antioxidant properties in protein hydrolysates of mackerel (Scomber austriasicus). Food Research International 36: 949-957.

Yarnpakdee, S., S. Benjakul, H.G. Kristinsson, and H. Kishimura. (2015). Antioxidant and sensory properties of protein hydrolysate derived from Nile tilapia (Oreochromis niloticus) by one- and two-step hydrolysis. Journal of Food Science and Technology-Mysore 52: 3336-3349.

Yarnpakdee, S., S. Benjakul, S. Nalinanon, and H. G. Kristinsson. (2012). Lipid oxidation and fishy odour development in protein hydrolysate from Nile tilapia (Oreochromis niloticus) muscle as affected by freshness and antioxidants. Food Chemistry 132: 1781-1788.

Zayas, J.F. (1997). Foaming properties of proteins. In Functionality of proteins in food (pp. 260-309): Springer.

Zhang, Y., Y. Zhang, X. Liu, L. Huang, Z. Chen, and J. Cheng. (2017). Influence of hydrolysis behaviour and microfluidisation on the functionality and structural properties of collagen hydrolysates. Food Chemistry 227: 211-218.

Zlatanos, S., K. Laskaridis, C. Feist, and A. Sagredos. (2006). Proximate composition, fatty acid analysis and protein digestibility-corrected amino acid score of three Mediterranean cephalopods. Molecular Nutrition and Food Research 50: 967-970. 